\title{
Effect of Cavities on the Behaviour of Model Pile under Axial Loading in Sand
}

\author{
Ali Al-Jazaairry, Tahsin Toma Sabbagh \\ University of Salford \\ Manchester, UK \\ a.a.s.al-jazaairry@edu.salford.ac.uk; t.toma@salford.ac.uk
}

\begin{abstract}
Presence of cavities in soils is an important area of interest within the field of geotechnical engineering. A better understanding of the behaviour of such soils, particularly in locations where the presence of gypsum deposits is apparent, will have a large impact on the stability of foundations and allows designers and engineers to have a convincing explanation of this phenomenon on the stability of foundations in general. The research offers an experimental investigation to study the performance of axially loaded piles embedded in sandy soils with cavities. The experimental study comprised a full laboratory testing programme carried out on small scale piles embedded in predetermined cavities within a soil mass. The experimental model has the capability to investigate the effect of different cavity locations on the ultimate pile resistances. Thirteen cavity locations were chosen to study their influence on the ultimate carrying load of single pile. It was concluded that the maximum ultimate carrying load of the pile is reduced by the presence of the cavity within the soil mass. This reduction varies according to the cavity location. The effect of cavity's presence on the ultimate bearing capacity of pile ranged from $0 \%$ to $30.82 \%$ for side cavities, while the range of reduction factor for cavities under the pile tip is from $31.58 \%$ to $43.4 \%$. The reduction in pile capacity increases when the cavity is closer to the pile. Also, pile settlement value without cavity is less than the settlement of the same pile with cavity.
\end{abstract}

Keywords: Axial load, Cavity, Pile, Sand

\section{Introduction}

Unlike most structural materials, behaviour of soils is regarded as complicated material. These soils have to be dealt with carefully to use the structures built on them safely. One of the most common problems in soils is the presence of cavities. Soils comprise cavities are usually titled "problematic soils" since cavities might cause structural destruction and loss of life. Cavities can be divided into two types, natural and man-made cavities. Natural cavities are due to extinction (dry set) of some seas or water areas, dissolvable materials including limestone, salt, dolomite and mainly gypsum and thawing of subsurface ice lenses. Different sizes of cavities in sandy soil ranging from $100 \mathrm{~mm}$ to $3000 \mathrm{~mm}$ have been encountered by [1] as illustrated in Fig. 1. Artificial cavities are due to tunnelling or mining activities, underground piping maintenance and old conduits vault (oldest) building. Therefore, the sudden failure of structures founded on these soils is normal to happen due to the formation of cavities before or after load application. Moreover, when structures are constructed on soils with cavities, cracks develop within the walls and roofs of the buildings due to the differential settlement.

Piles are the most common deep foundation elements which are used for transmission the external loads to inferior layers within the soil mass. This transference might be done by a straight load application to a lower level over the pile point, or the vertical load distributes along the pile shaft. A direct load application is made by an end-bearing pile, and a vertical load distribution is through using a floating (or friction) pile [2].

\section{Previous Work}

Investigations on the performance of piles above cavities are limited in the available literature; merely rare studies associated with this topic matter are available. [3] studied the behaviour of strip foundation located on a continuous void. An evaluation was made for two cases, one for without void condition and another for the void at 102 mm beneath the footing. The load carrying capacity of the foundation for each test condition was acquired from the point at which the slope 
of the foundation pressure versus settlement curve becomes a minimum constant value. [4] investigated cavity influence on the stability of strip foundation in two layer soils. For each soil layer, the ultimate bearing capacity for no cavity case was also determined. The no cavity bearing capacity value was used to obtain the reduction factor for each condition.

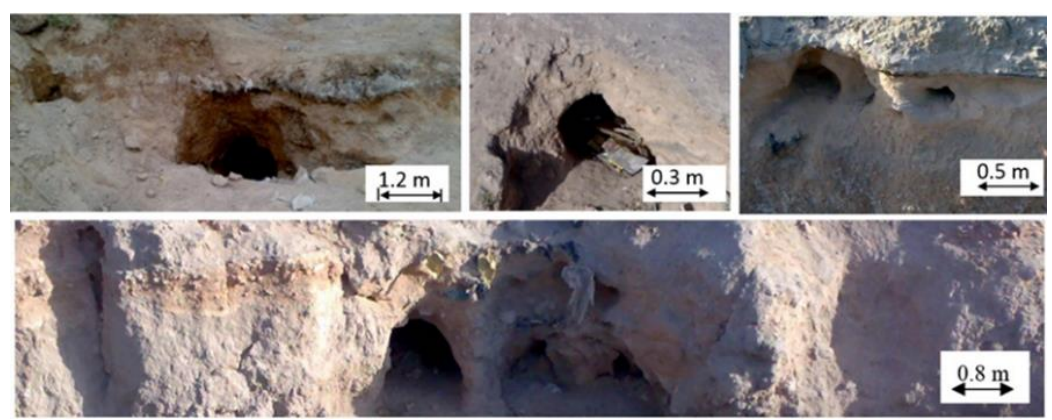

Fig. 1: Photographs for different cavities with different sizes and locations in Al-Najaf city / Iraq [1].

[5] studied the influence of tunnelling prompt soil movements on piles. The outcomes revealed that for the condition of a single friction pile, generated bending moments are normally slight when the horizontal distance between the pile and the centre of the tunnel is more than 2 tunnel diameter. [6] examined the performance of piles embedded in sandy soils, which contain cavities, under lateral load. It has been found that the number and location of cavities have a combined impact on the behaviour of the pile under lateral load. The influence of cavities situated in front of the pile is negligible at $X / D>8$ where $X$ is the distance between pile and cavity and $D$ is the pile's diameter. [1] investigated the behaviour of a laterally loaded pile embedded into the cohesionless soil of Al-Najaf city with the cavity. The experimental results indicated that the model tests for a shallow or very deep cavity with negative distance ratio (the ratio of the horizontal distance between cavity and pile to pile width $=-8$ ) bears more load than the condition of positive distance ratio. The effect of the cavity presence on the nearby buildings particularly piled structures has been studied by [7]. [8] utilised the finite element software (PLAXIS) to inspect load carrying capacity and failure mechanism of strip foundation situated on soil with twin voids. They proposed that a critical distance between voids and a critical depth of them occur in which there was no influence of voids on the ultimate capacity of foundation. This study presented an experimental and numerical analysis to examine the behaviour of pile model embedded in sand of dry unit weight $16.8 \mathrm{kN} / \mathrm{m}^{3}$. The settlement of the pile embedded in soil without a cavity is much less than that with the cavity; the reduction ratio is about $60 \%-70 \%$.

The previous revision showed a necessity to improve the stability analysis method for piled foundations placed in cavited soil. An important element required for the development is the pile's ultimate carrying capacity and displacement behaviour. This paper offers the bearing capacity behaviour of floating pile embedded in sandy soil with cavities. As a model study on this topic, this study is limited to floating pile located close to continuous cavities of regular shape and subjected to vertical central loading.

\section{Bearing Capacity of Piles}

The main factors in which the bearing capacity of foundations relies on are the water conditions in the soil, original stresses, and the mechanical properties of the soil, such as shearing strength, deformation characteristics, density, the physical characteristics of the foundation, such as shape, size, roughness, and depth and the installation method [9]. However, [9] and [10] suggested the failure zone near the pile base. It has been believed that the failure zone is mainly shear failure kind as well as the rupture surfaces expand to a specific distance over the pile tip. It is suggested that the failure zone shape is a logarithmic spiral. Additionally, the failure zone height raises by the increasing in soil friction angle.

The methods of determining failure loads are based on load-displacement curves. A failure load, as suggested by Terzaghi, might be defined as that which produces a displacement equal to 10 percent of the pile width or diameter which is commonly taken by engineers. However, there are some other reported criteria for describing the load at failure of piled foundations. 


\section{Sand Properties}

The soil used is Leighton Buzzard silica sand from Leighton Buzzard town in Bedfordshire, England. Standardised tests were conducted to reveal the physical and engineering properties of the sand according to the BS specifications. The grain size distribution of the sand used is shown in Fig. 2, whereas details of the soil properties are shown in Table 1.

For quality assurance, the particle size distribution tests were performed on four soil samples. The angle of internal friction is concluded by performing the direct shear box test which was conducted at a unit weight of $16.5 \mathrm{kN} / \mathrm{m}^{3}$.

Table 1: Physical properties of the soil used in the tests.

\begin{tabular}{|c|c|c|c|}
\hline Index property & Unit & Value/description & Specification \\
\hline Specific gravity, $G s$ & & 2.66 & BS $1377-2$ \\
\hline Effective size $D_{10}$ & $\mathrm{~mm}$ & 0.24 & BS $1377-2$ \\
\hline $\mathrm{D}_{30}$ & $\mathrm{~mm}$ & 0.38 & BS 1377-2 \\
\hline Mean grain size $D_{50}$ & $\mathrm{~mm}$ & 0.46 & BS 1377-2 \\
\hline $\mathrm{D}_{60}$ & $\mathrm{~mm}$ & 0.49 & BS $1377-2$ \\
\hline Particle size range & $\mathrm{mm}$ & $0.063-1.18$ & Sieve analysis \\
\hline Coefficient of uniformity, $C_{u}$ & & 2.04 & ASTM \\
\hline Coefficient of curvature, $C_{c}$ & & 1.23 & ASTM \\
\hline Soil classification & & SP* & $\mathrm{USCS}^{* *}$ \\
\hline Soil Textural Classification & & Sand & $\mathrm{USDA}^{* * * *}$ \\
\hline AASHTO classification & & A-3 & AASHTO***** \\
\hline Maximum dry unit weight $\gamma_{d(\max )}$ & $\mathrm{kN} / \mathrm{m}^{3}$ & 18.14 & BS $1377-4$ \\
\hline Minimum dry unit weight $\gamma_{d(\min )}$ & $\mathrm{kN} / \mathrm{m}^{3}$ & 15.51 & BS 1377-4 \\
\hline Angle of internal friction $(\Phi)$ at $D r=17$ & degree & 38.6 & BS 1377-7 \\
\hline
\end{tabular}

${ }^{*} \mathrm{SP}=$ Sand, Poorly graded.

${ }^{* *}$ USCS = Unified Soil Classification System

${ }^{* * *}$ USDA = U.S. Department of Agriculture.

$* * * *$ AASHTO $=$ American Association of State Highway and Transportation Officials

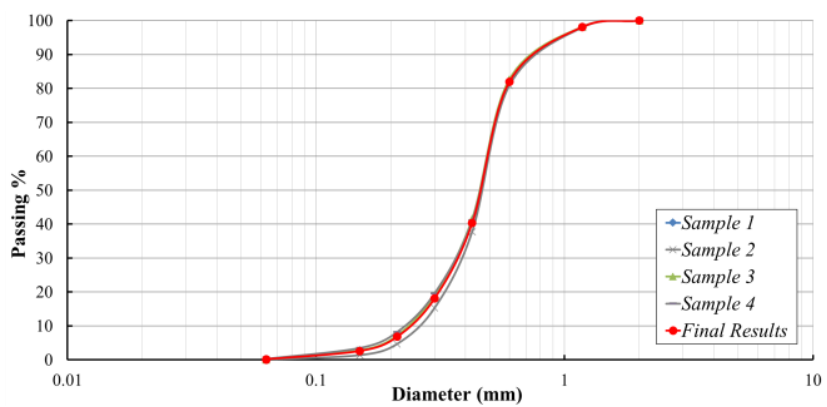

Fig. 2: Grain size distribution curve of soil sample.

\section{Testing Apparatus}

The experimental work has been carried out in the heavy structure's Laboratory of the school of computing, science and engineering at the University of Salford. The testing apparatus, see Fig. 3, consists of loading unit, reaction frame, pile model, temporary pile holder, box of test soil and measuring system. These units have been employed to simulate soil-pilecavity system in order to study the influence of the presence of cavity in different locations on the load carrying capacity of the single pile.

\subsection{The Loading Unit}

The loading unit consists of screw jack attached to the electronically controlled motor. The screw jack has a maximum capacity of $5 \mathrm{kN}$. During the experimental test programme, the rate of the load was kept unchanging at $1 \mathrm{~mm} / \mathrm{min}$, refer to [11]. Additionally, the loading unit consists of reaction frame used for holding loading unit. It consists of vertically movable arm which is raised by a hydraulic jack and supported by two tension bars to prevent the arm from moving upward during load application period. The loading system is shown in Fig. 3 and Fig. 4. 


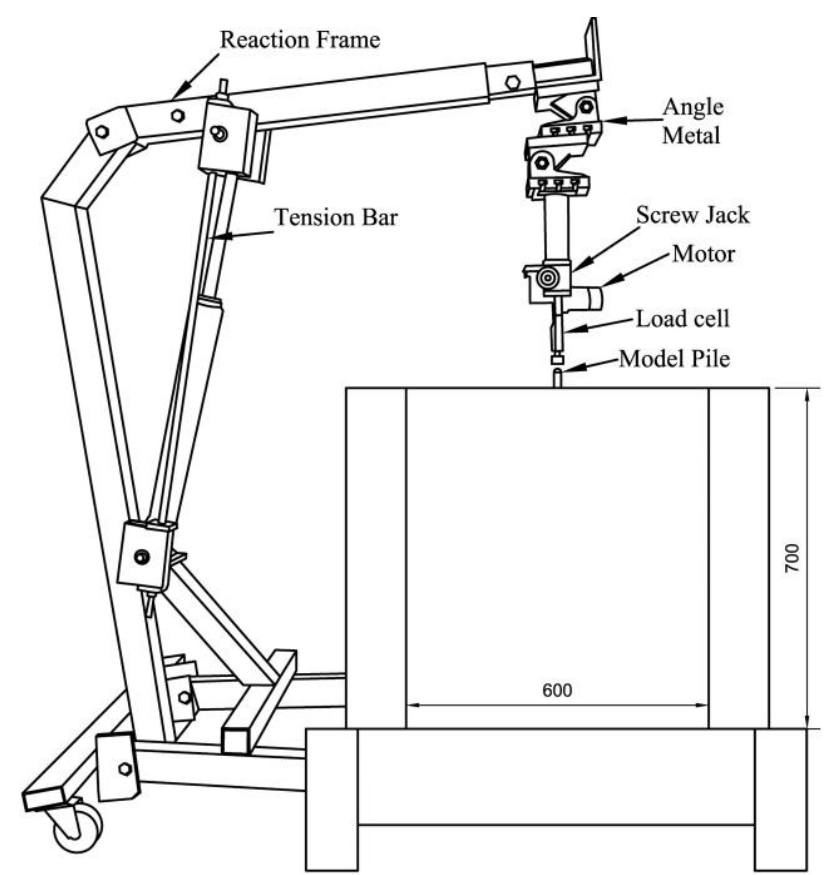

Fig. 3: Schematic diagram of the test setup.

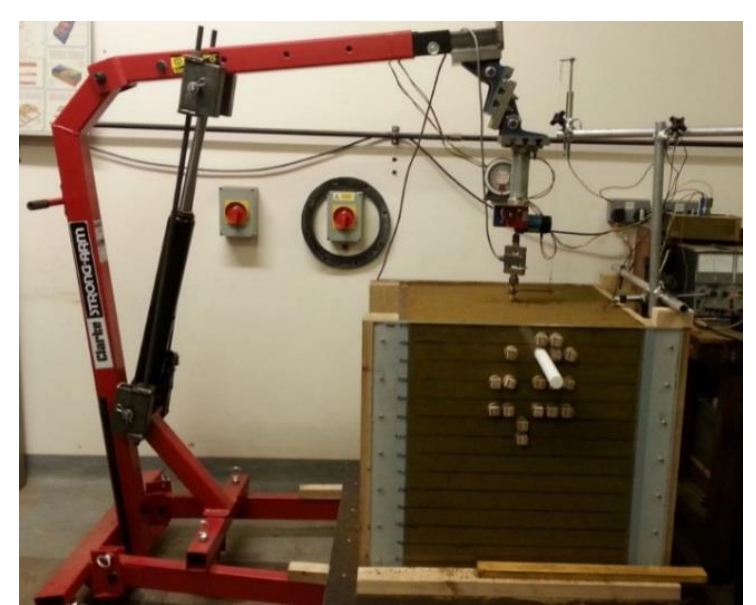

(a)

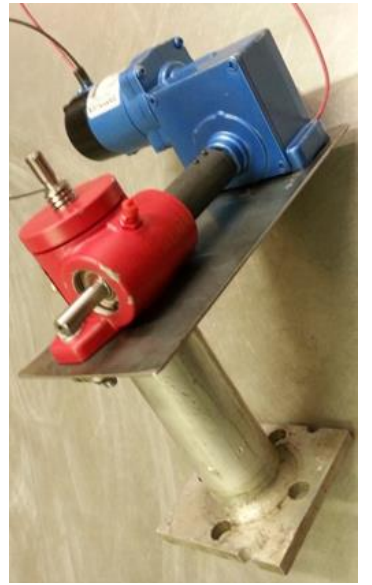

(b)

Fig. 4: Load Application System (a) The whole reaction Frame (b) Screw jack attached to the motor.

\subsection{Model Pile}

The model piles used in this study are rough aluminium pipe piles. The model pile surface has been made rough by gluing dry sand particles carefully on the shaft and bottom of the pile as suggested by [12] and [13] to simulate soil to soil interaction and to develop frictional properties of the pile. The outside diameter of pile is $18 \mathrm{~mm}$, and the wall thickness is $1.7 \mathrm{~mm}$, whereas the pile length is kept at $255 \mathrm{~mm}$ at all stages of the testing programme, whereas the free length of the pile above the sand bed level is maintained at $25 \mathrm{~mm}$.

A free head pile condition is maintained for load application at all stages. In order to achieve this, a smooth hemisphere metal ball is welded to the head of the pile model. A temporary pile holder was manufactured to keep the pile in position while the sand is being put in the test box. After completing this stage, the pile holder is raised up. 


\subsection{Testing Box}

A wooden test box (container) has been used with inside dimensions of $(600 \mathrm{~mm})$ in width, $(600 \mathrm{~mm})$ in length and $(700 \mathrm{~mm})$ in height. The dimensions have been chosen so that no wall effect will influence the tests. Upon selection of the box dimensions, the following points were taking into account:

1.Piled raft foundation under lateral loading, the size of the box should be extended up to $12 d$ and $4 d$, where $d$ is a pile diameter, in the direction parallel and perpendicular to the lateral load respectively. Additionally, a distance of at least $6 d$ must be kept below the pile tip, refer to [14].

2.To avoid the effect of tip resistance on diameter/width of the container, the ratio of the box diameter to the model pile diameter should be larger than 30 in sand [15], where this ratio in the current test is 40.

3.Effect of container walls might intensely decrease the vertical stress with depth, to prevent side friction of the container walls; the ratio of the box height to the diameter must be $\leq 1$ [16] and [17].

4. To eliminate the effects of box boundaries on the behaviour of axially loaded piled foundation, pile tip should be left for a distance greater than pile length $(l)$ from the container bottom [18].

\subsection{Sand density control technique}

Soil samples for all tests were prepared by filling dry soil in a temporary container, then $4 \%$ moisture content is gradually added to the mass of soil using a water sprinkler and mixed thoroughly with the soil. Care is taken to mix the water evenly. The temporary container is made of plastic to avoid any loss in moisture content during the mixing procedure. To maintain an equal density, the test box is divided into 14 layers by a permanent marker on glass sides, each layer with $50 \mathrm{~mm}$ in height. The wet soil is weighed on an electronic scale to the required weight, (to occupy one layer), for the aim of obtaining the soil unit weight. Then the mixture is spread inside the test box and compacted with wooden tamping hammer until the soil reached the height equivalent to $50 \mathrm{~mm}$. The compaction process was carefully performed to produce a homogeneous sample that could be used in a parametric study in a laboratory testing programme. This operation is repeated until the final height is reached.

\subsection{Forming of the Cavity}

Cavity locations have been chosen to be at certain distances from the pile as shown in Fig. 5. Those locations, both vertically and horizontally, have been taken and shown as percentages of pile diameter and pile length. Holes in both perspective glass sides were made according to these locations. A Teflon PolyTetraFluoroEthylene (PTFE) mold rod, with an outside diameter $(D)$ equals to $30 \mathrm{~mm}$, has been selected to create cavities. This material has been chosen because of its low coefficient of friction $(\mu s)$ comparing with other materials, $(\mu s=0.05-0.10)$. The Teflon rod placed in the required hole before filling the soil in the box to form the cavity in that specific location. Following the placement of the required Teflon rod, soil filling continued till the final level of the bed of soil (ground surface level) as shown in Fig. 4. Plugs, made of wood block and metal plate, are used to close the unused cavity openings in order to stop the soil extraction out from these openings. After placing the model pile and completion of the soil bed, the rod is pulled gently out of the container leaving formed cavity in the predetermined location as shown in Fig. 6.

\subsection{The Measuring System}

a. Displacement measurement

Vertical displacements of the model pile measured using Linear Variable Differential Transformer (LVDT) which connected to data logger. This LVDT has been connected to the pile using thin wires to avoid any interfering with loading system. 


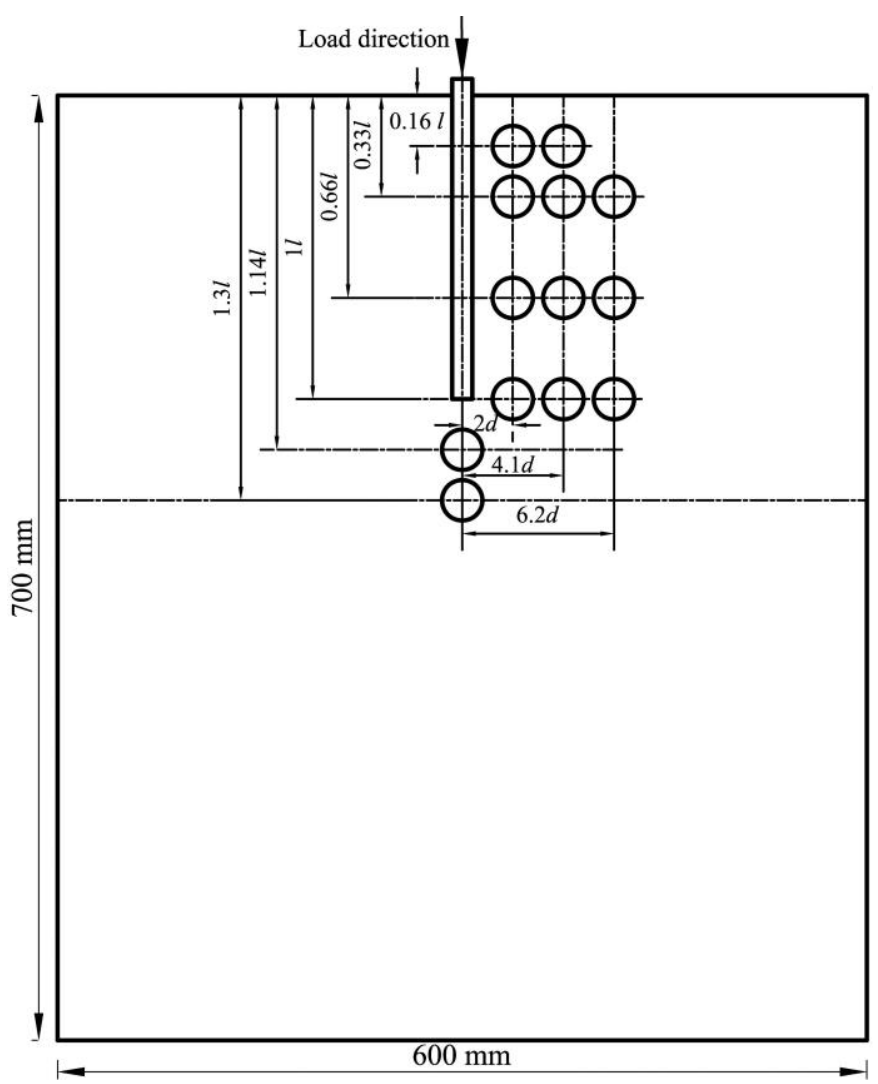

Fig. 5: Problem geometry showing pile and cavity locations in the test rig.

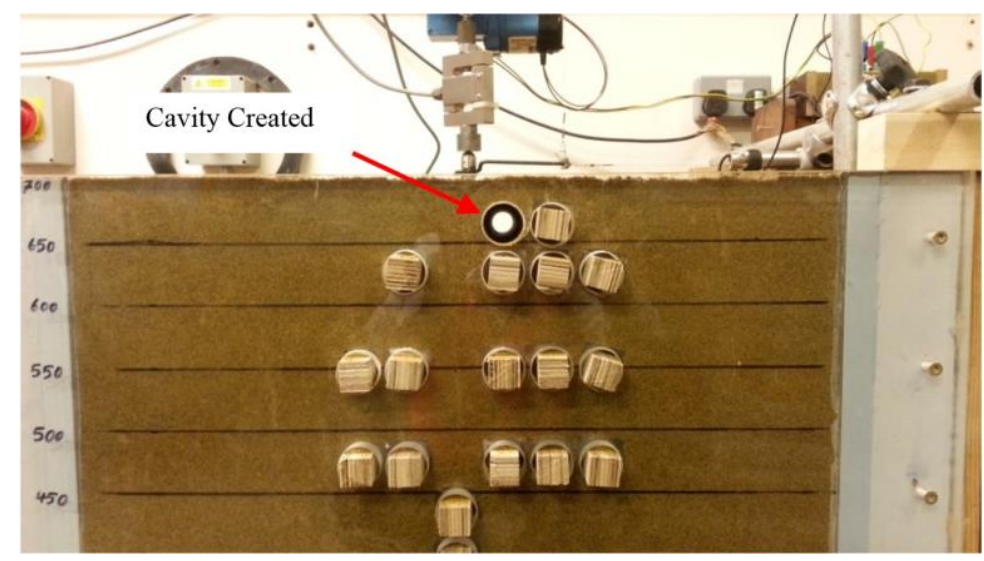

Fig. 6: Cavity Formed after removing Teflon rod.

\section{b. Load measurement}

A load cell was used to measure the applied load with a maximum capacity $200 \mathrm{~kg}$. A connection box is used to connect the load cell and the LVDT to the data logger in order to measure and display the load and displacements values on the computer. Computer software, Catman version 3.5, has been used to visualise and analyse measured data.

\section{Testing Programme}

The testing program was planned to consist of thirteen compressive tests on the vertical pile to study the effects of the presence of cavities on the performance of bored piles subjected to axial load. The depth of embedment of pile $(l=230$ $\mathrm{mm})$, pile length $(L=255 \mathrm{~mm})$, pile diameter $(d=18 \mathrm{~mm})$ and free length of the pile above the bed of the soil surface level equal to $(25 \mathrm{~mm})$. The cavity location was varied from $0 d$ to $6.2 d$ from pile centreline in horizontal direction and from 
$0.16 l$ to $1.3 l$ from the soil surface in vertical direction as shown in Fig. 5. In addition, one test without cavity has been conducted as reference test. In order to evaluate the repeatability and approve the reliability of the small scale laboratory test outcomes, a repetition of the original test with the same conditions has been carried out at least twice. Consequently, by conducting a sequence of check tests before starting to accept the test results, it has been found that changing in water content and soil unit weight has an appreciable effect on the test results. Therefore, to overcome this, the box fulling operation has followed a certain procedure by maintaining a soil layers technique and using Moisture Analyser device throughout all tests.

When piles are subjected to vertical loading alone, horizontal displacements are very small compared to vertical displacements. To facilitate comparisons between the different tests, the dimensionless geometric parameters are given in terms of the following forms:

$X / d=0,2,4.1$ and 6.2.

$Z / l=0.16,0.33,0.66,1,1.14$ and 1.3 .

\section{Experimental Results and Discussion}

This section includes discussion of the effects of the presence of cavities on the performance of vertically loaded piles. To facilitate comparisons between the model tests, the geometric parameters are presented in terms of the following dimensionless forms:

$(X / d)$ : the ratio of cavity horizontal distance from pile centreline to pile diameter, $X / d=0,2,4.1$ and 6.2.

$(Z / L)$ : the ratio of the depth of the cavity to the pile embedment length, $Z / L=0.16,0.33,0.66,1,1.14$ and 1.3.

Reviewing the load-displacement curves for all tests shows that these curves do not show a peak behaviour, with the axial loading increasing with the increase of pile displacement. Therefore, failure loads for the current set of tests were evaluated using the load required to produce a displacement corresponding to $10 \%$ of the pile diameter as suggested by [19]. Generally, the $10 \%$ pile diameter method gives the lowest value of failure load comparing with other failure criteria. Moreover, the results of the tests are presented as relationships between the load in the pile that represents the load cell indicator readings and the settlement that represents the LVDT readings.

Fig. 7 illustrates the load-displacement curve of single pile embedded in soil without cavity as a reference case as well as cavities in different locations. Fig. 7(a) shows the load-settlement curves of single pile embedded in soil with $X=0 d$ at different depths, while Fig. 7(b) presents the load-displacement curves of single pile embedded in soil with $X=2 d$ at different depths. Similarly, Fig. 7(c) and Fig. 7(d) reveals the load-displacement curves of single pile embedded in soil at different depths with $X=4.1 d$ and $X=6.2 d$ respectively.

Table 2 shows the values of the failure load obtained from laboratory tests. From this table, it can be seen that the cavity presence in the soil decreases the load carrying capacity of the pile. The reduction factor in the ultimate pile capacity is defined as:

$$
\text { Reduction Factor }=\frac{\text { load without cavity }- \text { load with cavity }}{\text { load without cavity }}
$$

Table 3 reveals the values of the reduction factor in percent for all cavities in different cavity locations. The summary of the effect of the cavity location of the ultimate carrying load of the pile is illustrated in Fig. 8 as a reduction factor in percent versus $Z / l$ ratio for different $X / d$ ratios. To simplify the effect of the cavity locations on the load carrying capacity of floating pile, the reduction factors in percent of each cavity position have been drawn in Fig. 9. 


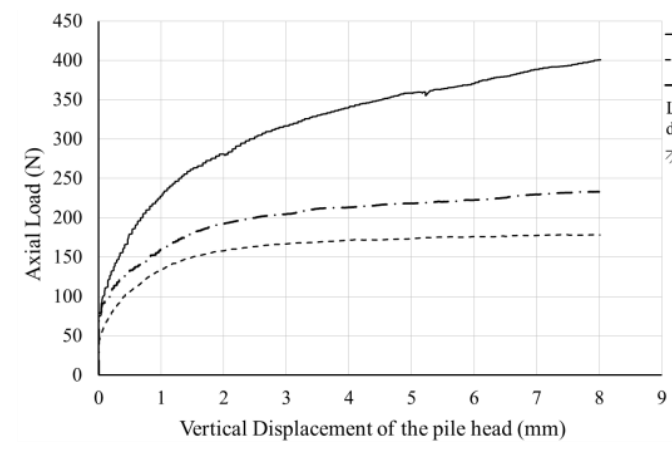

(a)

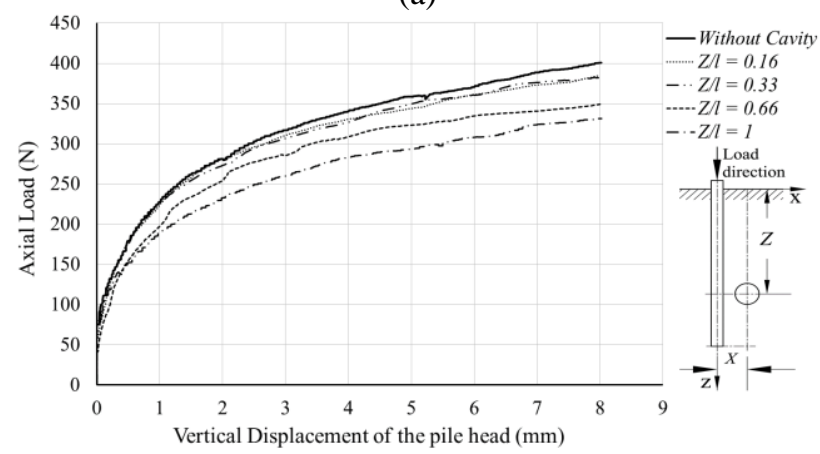

(c)

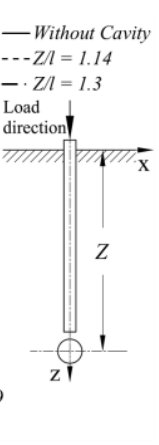

Without Cavity $\mathrm{Z} /=0.16$ $\begin{aligned}-\cdot Z l & =0.33 \\ -Z Z & =0.66\end{aligned}$ $-\cdot-\mathrm{Z} /=1$ Load

Fig. 7: Load-displacement curves of pile embedded in soil with cavity at different depth

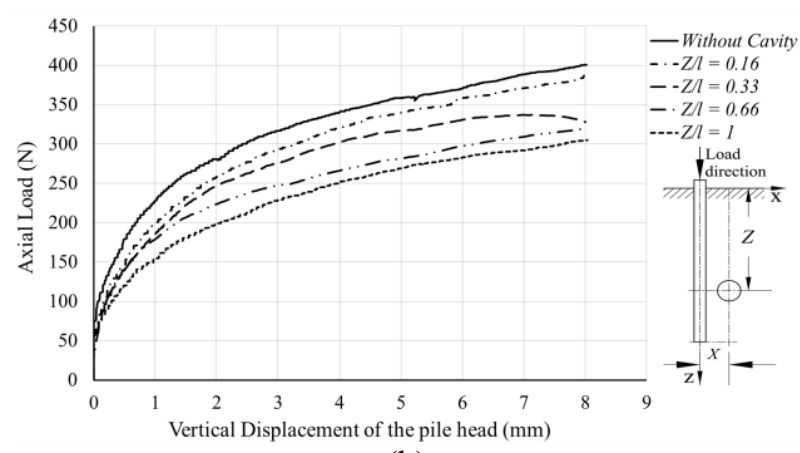

(b)

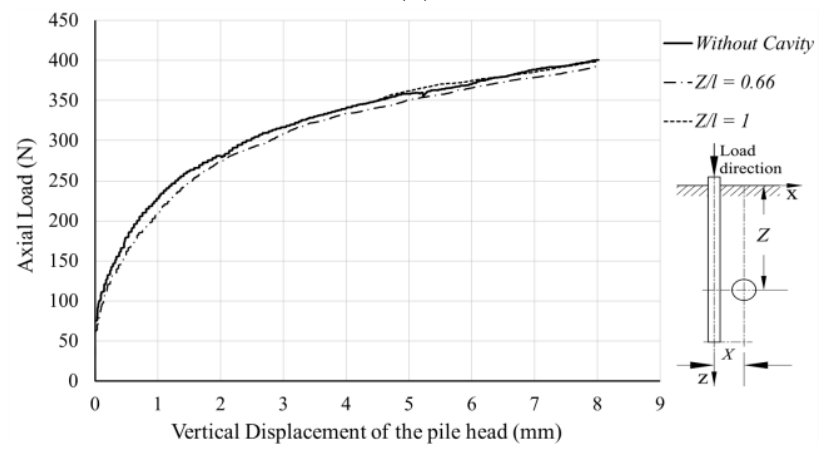

(d)

Table 2: Failure load $(\mathrm{N})$ of single pile embedded in soil with and without cavity obtained from laboratory tests.

\begin{tabular}{|l|c|c|c|c|}
\hline$Z$ & $0 d$ & $2 d$ & $4.1 d$ & $6.2 d$ \\
\hline $0.16 l$ & & 248.48 & 273.5 & \\
\hline $0.33 l$ & & 238.1 & 266.5 & \\
\hline $0.66 l$ & & 216.5 & 246.35 & 264.3 \\
\hline $1 l$ & & 190.64 & 225.75 & 274.7 \\
\hline $1.14 l$ & 155.9 & & & \\
\hline $1.3 l$ & 188.55 & \multicolumn{5}{|c|}{275.6} & \\
\hline Without cavity & \multicolumn{5}{|l|}{} \\
\hline
\end{tabular}

Table 3: Reduction factor (\%) of different cavity location obtained from laboratory tests.

\begin{tabular}{|l|c|c|c|c|}
\hline$Z$ & $0 d$ & $2 d$ & $4.1 d$ & $6.2 d$ \\
\hline $0.16 l$ & & 9.84 & 0.76 & \\
\hline $0.33 l$ & & 13.6 & 3.3 & \\
\hline $0.66 l$ & & 21.44 & 10.6 & 4.1 \\
\hline $1 l$ & & 30.82 & 18.08 & 0.32 \\
\hline $1.14 l$ & 43.43 & & & \\
\hline $1.3 l$ & 31.58 & & & \\
\hline
\end{tabular}

It is assumed that, from Fig. 9, the very small values of reduction factor represent the boundary of failure zone surrounding the pile. This zone is compared with that suggested by [9] and [10]. There is a similarity in shape between the experimentally achieved failure zone and the failure zone presented by [9] and [10]. However, the main portion of the failure zone is found over the pile tip in the empirical results while the experimental results showed that the failure zone develops further lower the pile tip. This is because of [9] and [10] supposed that the procedure of shear failure happens nearby the pile tip. The experimental results conducted in this study revealed that the pile is reliant on the soil found underneath the pile tip more than those situated over the pile tip. 

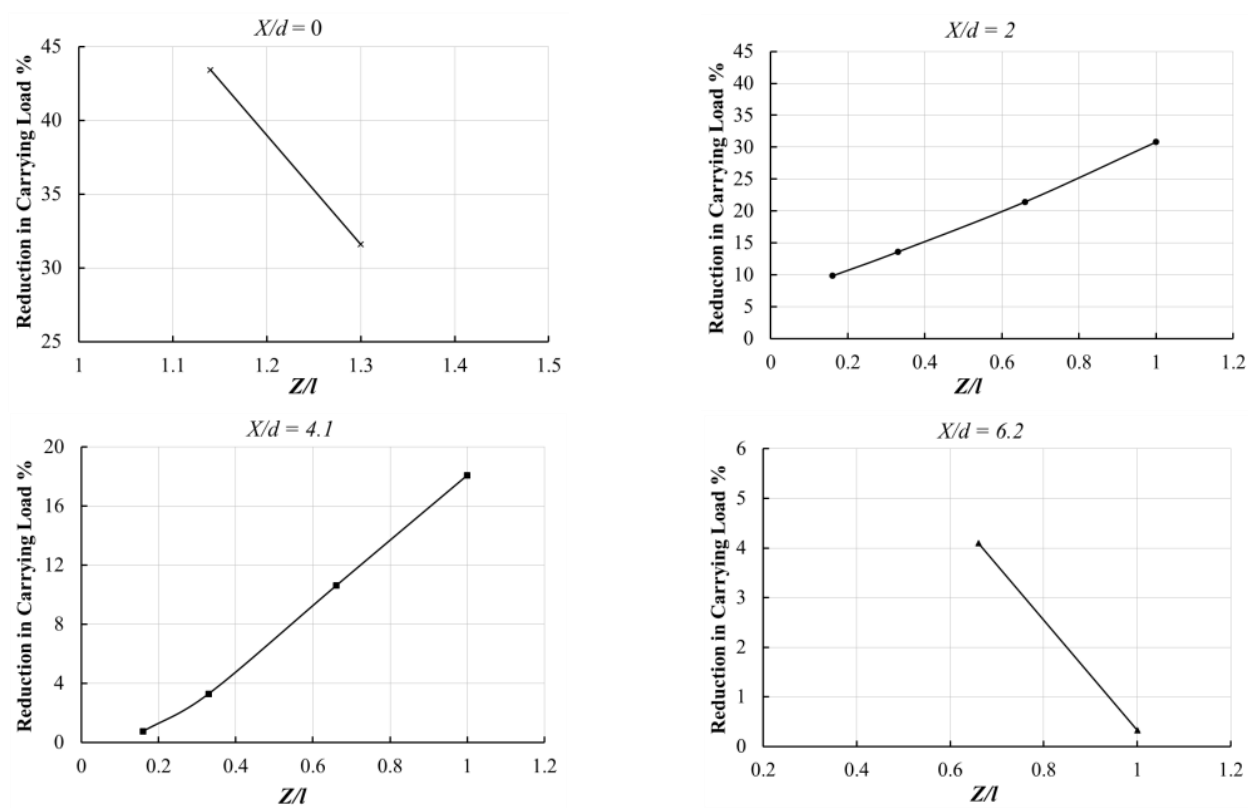

Fig. 8: Reduction in carrying loads versus $Z / L$ for different $X / d$.

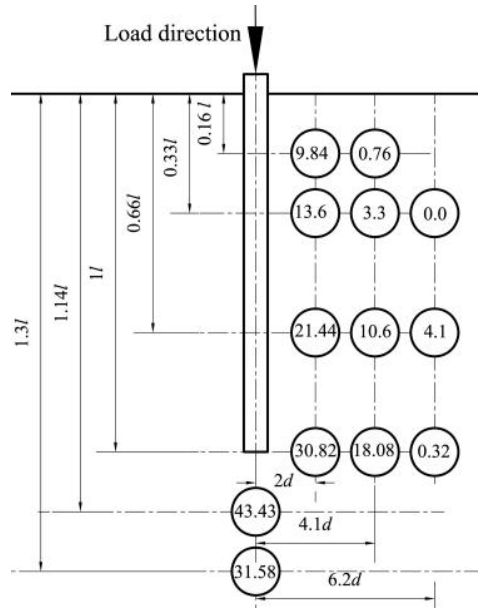

Fig. 9: Reduction factor $(\%)$ of different cavity locations obtained from laboratory tests.

\section{Conclusion}

The results that are obtained from the laboratory tests have revealed the effect of cavity presence on the flexible pile behaviour in sandy soil. Below are the conclusions that can be drawn from the achieved experimental results.

1.The pile settlement reduces with the increase of the ratio of the horizontal distance of cavity centreline to pile diameter $(X / d)$.

2.The influence of the cavity position in horizontal distance $X / d \geq 6.2$ can be neglected when the ratio between the cavity depth to pile length $Z / l \leq 0.33$ or $Z / l \geq 1.0$.

3. Maximum reduction factor of $43.4 \%$ and $31.6 \%$ was achieved at $X / d=0$ and at cavity depth $Z / l$ equals to 1.0 and 1.3 respectively.

4. When $X / d=2$ the reduction factor ranged from 9.84 to 30.82 at cavity depths $Z / l$ of 0.16 and 1.0 respectively. Moreover, for $X / d=4.1$ the reduction factor is about ( $0.8 \%$ to $18 \%$ ) at cavity depth $Z / l$ of 0.16 and 1.0 respectively.

5.The range of the influence of side cavities is from $0 \%$ to $30.82 \%$ from the load carrying capacity of pile whereas the range of cavities under the pile tip is from $31.58 \%$ to $43.4 \%$.

6.Based on the experimental results, the influence of the cavity position in horizontal distance $X / d \geq 6.2$ can be neglected when the ratio between the cavity depth to pile length $Z / \leq 0.66$. 
7.Experimental analysis illustrates that the failure zone near the pile tip is generally extended beneath the pile tip. This lead to conclude that the load carrying capacity of piles is reliant on the soil properties located beneath the pile base more that those situated over the pile tip.

It is to note that the pile load carrying capacity improves with the increase of the $\mathrm{X} / \mathrm{d}$ ratio in all occasions and it can be attributed to the following reasons:

1.Decrease of the effective zone influenced by the presence of cavity.

2. When the cavity is located at close range to the pile, it will reduce the soil density at that zone and hence decreases the shaft friction along the pile and leads to a decrease in the pile failure load.

3. At large distances from the pile; $(X / d=6.2)$, the reduction factor was found to decrease especially at $(Z / l=1.0)$.

\section{References}

[1] L. J. Aziz, "Lateral Resistance of Single Pile Embedded in Sand with Cavities," in Ph.D. thesis, University of Technology, Iraq, 2008.

[2] J. E. Bowles, Foundation analysis and design, 5th ed. McGraw-Hill International Book Company, 1988.

[3] A. Badie, M. C. Wang, "Stability of Spread Footing above Void in Clay," Journal of Geotechnical EngineeringAsce, vol. 110, no. 11, pp. 1591-1605, 1984.

[4] G. Azam, M. Jao, M. C. Wang, "Cavity effect on stability of strip footing in two-layer soils," Geotechnical Engineering, vol. 28, no. 2, 1997.

[5] C. Y. Cheng, G. R. Dasari, C. F. Leung, Y. K. Chow, H. B. Rosser, "3D numerical study of tunnel-soil-pile interaction," Tunnelling and Underground Space Technology, vol. 19, no. 4, pp. 381-382, 2004.

[6] M. J. Al-Mosawe, Y. J. Al-Shakarchi, S. M. Al-Taie, "Embedded in sandy soils with cavities," Journal of Engineering, vol. 13, no. 1, pp. 1168-1187, 2007.

[7] H. H. Abed, "Effect of Cavity in Sandy Soil on Load Distribution of Pile Group," in the Building and Construction Engineering Department, University of Technology, Iraq, 2013.

[8] A. A. Lavasan, A. Talsaz, M. Ghazavi, T. Schanz, "Behavior of Shallow Strip Footing on Twin Voids," Geotechnical and Geological Engineering, pp. 1-15, 2016.

[9] G. G. Meyerhof, "The ultimate bearing capacity of foudations," Geotechnique, vol. 2, no. 4, pp. 301-332, 1951.

[10] E. E. De Beer, "The scale effect in the transposition of the results of deep-sounding tests on the ultimate bearing capacity of piles and caisson foundations," Geotechnique, vol. 13, no. 1, pp. 39-75, 1963.

[11] J. E. Bowels, Engineering Properties of Soils and Their Measurement 2ed: McGraw-Hill International Book Company, Tokyo, Japan, 1978.

[12] S. Roy, B. C. Chattopadhyay, R. B. Sahu, "Pile behavior under inclined compressive loads-a model study," Electronic Journal of Geotechnical Engineering, vol. 18, pp. 2187-2205, 2013.

[13] Y. J. Al-Shakarchi, M. Y. Fattah, I. K. Kashat, "The behaviour of batter piles under uplift loads," in Proceedings of international conference on geotechnical engineering, Sharjah. 2004.

[14] M. Khari, K. A. Kassim, A. Adnan, "An experimental study on pile spacing effects under lateral loading in sand," Scientific World Journal, pp. 1-8, 2013.

[15] M. D. Bolton, et al., "Centrifuge cone penetration tests in sand," Geotechnique, vol. 49, no. 4, pp. 543-552, 1999.

[16] O. Ternet, "Reconstitution et caractérisation des massifs de sable: application aux essais en centrifugeuse et en chambre de calibration," Université de Caen, 1999.

[17] J. Garnier, "Physical models in geotechnics: state of the art and recent advances," in First Coulomb lecture, Caquot Conference, Paris, 2001.

[18] K. Horikoshi, M. F. Randolph, "Estimation of overall settlement of piled rafts," Soils and Foundations, vol. 39, no. 2, pp. 59-68, 1999.

[19] K. Terzaghi. Theoretical Soil Mechanics, John Wiley \& Sons, New York, 1943. 